\title{
A chemistry-transport model simulation of middle atmospheric ozone from 1980 to 2019 using coupled chemistry GCM winds and temperatures
}

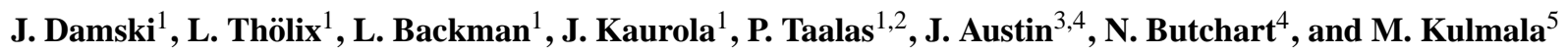 \\ ${ }^{1}$ Research and Development, Finnish Meteorological Institute, P.O.Box 503, FI-00101 Helsinki, Finland \\ ${ }^{2}$ Regional and Technical Cooperation for Development Department (RCD), World Meteorological Organization, case Postale \\ 2300, CH-1211 Genève 2, Switzerland \\ ${ }^{3}$ Geophysical fluid dynamics Laboratory, Princeton, NJ, USA \\ ${ }^{4}$ Climate Research Division, Met Office, Exeter, UK \\ ${ }^{5}$ Department of Physical Sciences, University of Helsinki, P.O.Box 64, FI-00014 Helsinki, Finland
}

Received: 15 December 2006 - Published in Atmos. Chem. Phys. Discuss.: 24 January 2007

Revised: 19 April 2007 - Accepted: 20 April 2007 - Published: 2 May 2007

\begin{abstract}
A global 40-year simulation from 1980 to 2019 was performed with the FinROSE chemistry-transport model based on the use of coupled chemistry GCM-data. The main focus of our analysis is on climatological-scale processes in high latitudes. The resulting trend estimates for the past period (1980-1999) agree well with observation-based trend estimates. The results for the future period (2000-2019) suggest that the extent of seasonal ozone depletion over both northern and southern high-latitudes has likely reached its maximum. Furthermore, while climate change is expected to cool the stratosphere, this cooling is unlikely to accelerate significantly high latitude ozone depletion. However, the recovery of seasonal high latitude ozone losses will not take place during the next 15 years.
\end{abstract}

\section{Introduction}

Long term stratospheric ozone change is a problem of great uncertainty and importance and is by no means solved. The interactions between climate change and stratospheric ozone depletion have already been recognised for a decade or so (see e.g. WMO, 2003). The link between climate change and stratospheric ozone depletion is usually studied using models. For studies of the past ozone behaviour, off-line chemistry-transport models (CTMs) using observed meteorological forcing can be used. In order to study the future ozone behaviour, coupled chemistry climate models (CCMs) are typically required. Since the physical and chemical in-

Correspondence to: J. Damski

(juhani.damski@fmi.fi) teractions are very complex, studies using models that are sophisticated enough have only been developed relatively recently. Several off-line chemistry-transport-type simulations using observed meteorological fields have been published in the field of stratospheric ozone depletion in recent years (e.g. Chipperfield, 1999; Rummukainen et al., 1999; Egorova et al., 2001; Hadjinicolaou et al., 2002; Chipperfield, 2003). A number of coupled chemistry-climate-model simulations have also recently been published. These include the works by e.g. Austin (2002); Austin and Butchart (2003); Austin et al. (2003a,b); Manzini et al. (2003); Nagashima et al. (2002); Steil et al. (2003); Tian and Chipperfield (2005); Austin and Wilson (2006); Eyring et al. (2006); Garcia et al. (2007). However, studies where the off-line CTM-approach has been used with meteorological forcings from coupled chemistry climate model integrations are uncommon. Such a study is e.g. the work by Brasseur et al. (1997). In this work this off-line CTM-approach combined with CCM data will be utilized for the study of both the past and future behaviour of the stratospheric ozone layer. The aim of this work is to drive an off-line chemistry-transport model with relatively detailed chemistry scheme using CCM output as a driver, and to address questions concerning the near past and near future stratospheric ozone concentration changes.

Recently there has been an active debate on the trends in stratospheric ozone and the possible signs of recovery of the ozone layer (Reinsel et al., 2005; Hadjinicolaou et al., 2005; Weatherhead and Andersen, 2006; Yang et al., 2006; Dhomse et al., 2006; Steinbrecht et al., 2006). The decrease in equivalent effective stratospheric chlorine (EESC) has led to expectations of a stabilisation in ozone or even signs of recovery of stratospheric ozone. A positive trend has been

Published by Copernicus GmbH on behalf of the European Geosciences Union. 
Table 1. Long-lived tracer amounts in the simulation (Austin and Butchart, 2003).

\begin{tabular}{lccccccccc}
\hline Year & 1980 & 1985 & 1990 & 1995 & 2000 & 2005 & 2010 & 2015 & 2020 \\
\hline $\mathrm{Cl}_{\mathrm{y}}(\mathrm{ppb})$ & 1.64 & 2.21 & 2.72 & 3.25 & 3.50 & 3.49 & 3.48 & 3.47 & 3.38 \\
$\mathrm{Br}_{\mathrm{y}}(\mathrm{ppt})$ & 8.8 & 9.7 & 11.3 & 14.1 & 16.9 & 18.7 & 18.6 & 18.0 & 17.4 \\
$\mathrm{NO}_{\mathrm{y}}(\mathrm{ppb})$ & 18.4 & 18.6 & 18.8 & 19.1 & 19.4 & 19.7 & 20.0 & 20.3 & 20.7 \\
$\mathrm{~N}_{2} \mathrm{O}(\mathrm{ppb})$ & 302 & 306 & 310 & 314 & 319 & 323 & 328 & 333 & 339 \\
$\mathrm{CH}_{4}(\mathrm{ppb})$ & 1603 & 1651 & 1700 & 1749 & 1810 & 1882 & 1964 & 2052 & 2145 \\
$\mathrm{CO}_{2}(\mathrm{ppm})$ & 337 & 346 & 355 & 365 & 375 & 385 & 395 & 406 & 417 \\
\hline
\end{tabular}

observed in mid latitude NH ozone since the mid-1990s, which has been attributed both to changes in atmospheric dynamics (increased planetary wave driving) as well as decreasing EESC. The reason for the change in dynamics is not fully understood, and could be either natural variability or driven by the climate change. The future evolution of the stratospheric ozone is therefore still uncertain.

The focus of this study is on climatological scale features such as regionally averaged seasonal ozone variations or year-to-year ozone variations in the high-latitude stratosphere. We will present the results of a global 40-year middle atmospheric simulation from 1980 until the end of 2019. We will show how the average high-latitude concentrations of stratospheric ozone, and ozone destruction have evolved during the past period (1980-1999), and how ozone is expected to evolve in the near future (2000-2019). The stratospheric processes affecting high latitude stratospheric ozone will also be analysed, and the trend analysis of the past and future periods will be shown and compared against measurements. The simulation has been performed with the global chemistry-transport model, FinROSE, described by Damski et al. (2007). For this study FinROSE model has been driven with the winds and temperatures from a transient simulation of the coupled chemistry climate model UMETRAC Austin and Butchart (2003), using specified concentrations of longlived tracers such as the well-mixed greenhouse gases.

\section{Simulation settings and driver data}

FinROSE is a global 3-D grid point model (Damski et al., 2007), which is originally based on the NCAR-ROSE-model (Rose, 1983; Rose and Brasseur, 1989). FinROSE is an offline chemistry transport model. The model includes 27 longlived species/families and 14 species that are assumed to be in photochemical equilibrium. Chemistry includes around 110 gas-phase reactions, 37 photodissociation processes and 10 heterogeneous reactions. Photodissociation coefficients are compiled using the PHODIS radiative transfer model (Kylling, 1992; Kylling et al., 1997) and used through lookup tables. The aerosol and polar stratospheric cloud (PSC) processing includes liquid binary aerosols (LBA), super- cooled ternary solutions (STS, PSC type Ib), nitric acid trihydrates (NAT, PSC type Ia), NAT-rock and water ice particles (ICE, PSC Type II) and sedimentation. Chemical kinetics used in this work are updated to follow JPL-2002 (Sander et al., 2003). For the transport of the model constituents a flux-form Semi-Lagrange Transport-scheme (Lin and Rood, 1996) is used. For more detailed description of the FinROSEmodel see (Damski et al., 2007).

The meteorology (i.e. winds and temperatures) used in this study was produced by the UMETRAC (Unified Model with Eulerian Transport And Chemistry). UMETRAC is a CCM based on the UK Met. Office's Unified Model (Cullen, 1993). The ozone fields predicted by the chemistry in UMETRAC are used in the model radiation scheme to couple the chemistry to the climate. In this study we have used a UMETRAC model integration completed for the period from January 1975 to January 2020 (Austin and Butchart, 2003). The integration was based on the use of observed sea surface temperatures and sea ice coverage for the past period (1980-2000). For the future period (2000-2020) UMETRAC used the results of a coupled ocean-atmosphere version of the Hadley Centres climate model (Williams, 2001).

The horizontal resolution in this 40-year FinROSE integration was $5.00^{\circ}$ by $11.25^{\circ}$ (latitude-longitude) with pole to pole latitudinal coverage. The vertical resolution of the simulation was around $2700 \mathrm{~m}$ at 24 pressure levels from surface up to $\sim 0.15 \mathrm{hPa}$ (or $\sim 62 \mathrm{~km}$ ). The vertical grid of the model uses every other point of that used in UMETRAC. For the horizontal grid, the wind and temperature values are interpolated from the UMETRAC three-dimensional daily values using bilinear interpolation. The vertical wind is solved in the FinROSE transport scheme.

The initial distributions of chemical constituents were taken directly from the UMETRAC integration. The boundary conditions were taken from UMETRAC monthly means. The chemical scheme in FinROSE does not include parametrizations for the source gases (e.g. CFCs and their chemistry). The concentrations of the long-lived tracers followed the projections defined in Austin and Butchart (2003). Halogen data and the well-mixed greenhouse gases are from Austin and Butchart (2003). The levels and expected future 
evolutions of long-lived species, relevant to this study are shown in Table 1. Atmospheric concentrations of long-lived tracers (Table 1) are constrained at each timestep by relaxation towards monthly mean zonal averages given by the driver model. The individual members in the chemical families $\left(\mathrm{NO}_{\mathrm{y}}, \mathrm{Cl}_{\mathrm{x}}\right.$ and $\left.\mathrm{Br}_{\mathrm{y}}\right)$, are constrained with respect to their relative contributions given by the chemistry scheme.

As a result of projections in well-mixed greenhouse gases and other long-lived constituents (Table 1) and chemistry climate coupling in the driver model, the UMETRAC simulation captured the main characteristics of observed stratospheric temperature trends and also indicated continued cooling of the stratosphere in the near future. The Antarctic cooling trend in the past in the UMETRAC results also clearly indicated a strong connection between Antarctic ozone depletion and cooling of the stratosphere (see Austin and Butchart, 2003).

\section{Transport characteristics of the 40-year CTM-simulation}

The ability of a model to reproduce the stratospheric BrewerDobson circulation can be estimated using an analysis of the simulated age of air. This has become a standard way for testing stratospheric transport models in general (see Waugh and Hall (2002) for a review). In this study the age of air (hereafter also AOA) is defined as the average amount of time spent by the air parcels for the transportation from the source areas to any specific latitude and altitude in the stratosphere. The AOA diagnostic was used to see how the transport forcing, provided by the UMETRAC, works with the FinROSE transport scheme in comparison with the observed BrewerDobson circulation. As stated by Hall et al. (1999), in most CTMs the propagation of the annual atmospheric oscillations is too rapid in the vertical direction, and the CTMs also typically underestimate the mean age of air throughout the stratosphere.

Figure 1 shows the evolution of the AOA tracer at the $10 \mathrm{hPa}$ level in FinROSE over the North and South Pole. Interannual variability is clearly seen in the peaks during the wintertime periods, as expected, with less interannual variability during the summer. Over the South Pole the maximum values are about three years, and the minimum summer values just below two years. Over the North Pole the maximum values are less than three years, and the minimum typically around two years. While the simulated general behaviour follows what is expected from observations and theory, the absolute values are significantly lower than those given in Waugh and Hall (2002). The evolution of the AOA tracer is stable throughout the 40-year simulation period, but the model seems to have a Brewer-Dobson circulation which is unrealistically fast.

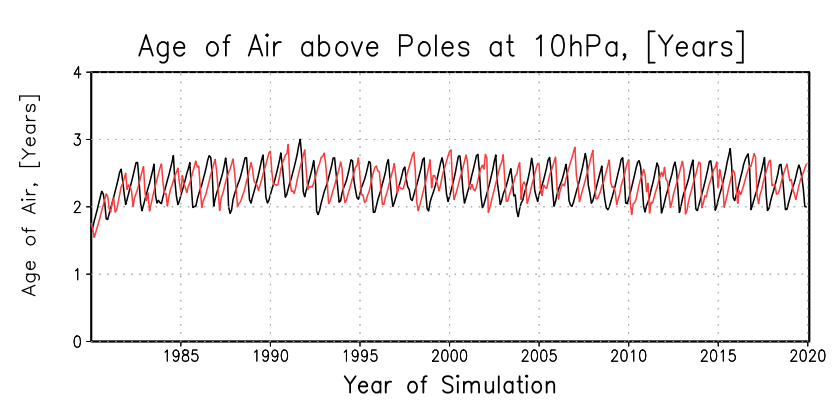

Fig. 1. The evolution of the age of air tracer above the South Pole (black line) and North Pole (red line) at $10 \mathrm{hPa}$ during the 40-year FinROSE simulation (in years).

\section{Simulated global annual ozone distribution}

A comparison of the model results with the ozone climatology compiled by Fortuin and Kelder (1998) is shown in Fig. 2. This climatology is based on ozonesonde measurements and satellite measurements of ozone, covering the period from 1980 to 1991. In Fig. 2 the same period was used for averaging the model results. The comparison shows that both models give reasonable and comparable results. However, there are discrepancies between the simulations and observations. The modelled ozone partial pressures are generally lower than observed in FinROSE, and higher than observed in UMETRAC.

In general the ozone maxima in FinROSE ozone distribution seems to be located higher up than in the measurements, while in the UMETRAC climatology the altitude matching seems to be better. The tropical ozone maximum in FinROSE is clearly too weak while in UMETRAC the opposite is true. Over the high southern latitudes the FinROSE data is in line with the measurements, since both the altitude and the magnitude compares well. The ozone distribution in FinROSE over the high northern latitudes is worse, as the partial pressure of ozone is too low while the height of the ozone maximum is reasonable. The height distribution of ozone in FinROSE yields to a lower column abundance, while in UMETRAC the higher partial pressure at more correct altitudes give too high ozone column abundances.

A general conclusion from Fig. 2 is that the FinROSE model reproduces the observed global patterns. The differences between the two models, as well as between models and measurements, seem to be connected with limitations and imperfections in the reproduction of the BrewerDobson circulation and with the differences in the stratospheric chemistry formulations in these two models.

UMETRAC includes the coupling between transport characteristics and atmospheric composition through radiation, i.e. the changes in the composition due to the chemical processing are reflected in the simulated temperatures and winds. Since the simulated composition is in balance with 


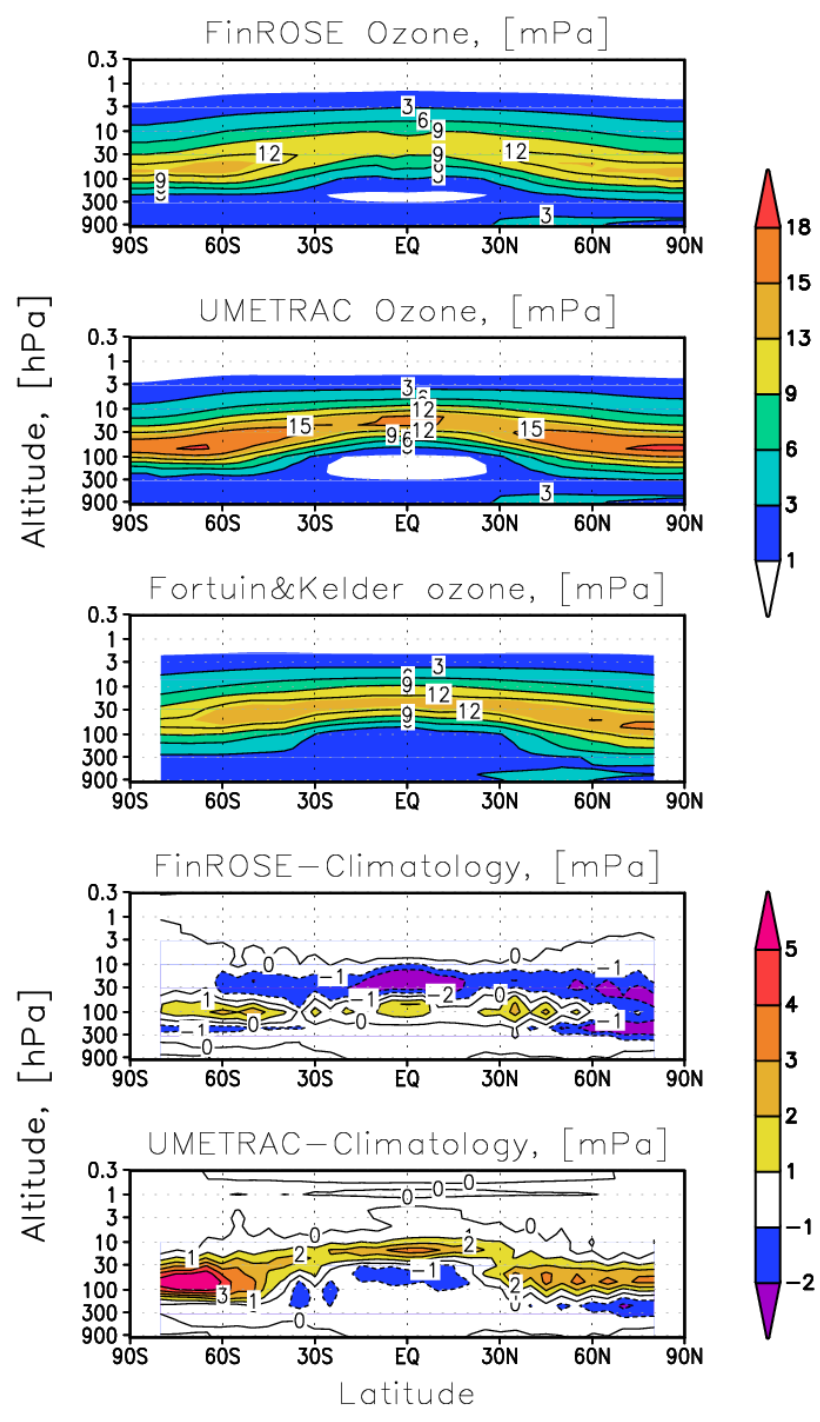

Fig. 2. Calculated model ozone climatologies for the period from 1980 to 1991, the measurement-based ozone climatology Fortuin and Kelder (1998), and respective differences. Values are shown as partial pressures $(\mathrm{mPa})$.

the dynamics, one may say that UMETRAC produces its own balanced aeronomy. When the winds and temperatures from such a model are introduced to a CTM where the transport is formulated in similar way, but chemical formulations are different, the realized compositional patterns end up being qualitatively the same, but quantitatively different. As Fig. 2 shows, the ozone climatologies derived from FinROSE and UMETRAC have differences e.g. in magnitude and altitude of the tropical ozone maximum. The tropical maximum can be considered the starting point for the Brewer-Dobson circulation, as new stratospheric air is injected from the troposphere mainly over the tropics. In FinROSE the maximum is located too high up, and in UMETRAC the tropical ozone maximum is too strong, i.e. the reproduced BrewerDobson circulation in FinROSE has less ozone to start with, and transport towards the winter pole, while UMETRAC has too much. An offset in the ozone maximum during late winter to early spring, also affects ozone amounts during summer and autumn.

\section{High latitude ozone evolution}

Figure 3 (upper panel) shows the percentage anomalies (from the 1980-1989 mean) in simulated total ozone enclosed by the 75th southern latitude for the 40-year simulation period in comparison to satellite-based TOMS-v8 and OMI total ozone measurements. Results from both the FinROSE and the UMETRAC simulations are shown. The FinROSE model reproduces all the observed main features, and the anomalies seen in the simulated ozone are of the same magnitude as in the TOMS measurements. The anomalies in the UMETRAC ozone are quite similar to the ones in FinROSE, although the total ozone levels are generally higher than measured.

In all cases the ozone hole starts to develop during JulyAugust, and ozone recovery is complete by the end of November or early December, meaning that the ozone depletion caught by the FinROSE model is well timed. Another well-reproduced element in Fig. 3 upper panel is the gradual increase of the Antarctic ozone anomaly in both models. Antarctic springs that exhibit no or very weak ozone depletion occur the same years in FinROSE and UMETRAC. The UMETRAC and FinROSE transport schemes end up in very similar results, and therefore the driver model determines mainly year to year and season to season variability. The differences in absolute levels between the models derive mainly from the differences in chemical formulations.

During the future period of the simulation (in Fig. 3) both models exhibit similar patterns in the month-to-month ozone anomalies, as they do during the past period. A comparison between the anomalies seen during the past years (i.e. 1980 to 1999) and during the near future (i.e. from 2000 to 2019) suggests that in the near future the behaviour of ozone will be similar to that observed during the 1990s.

The ozone anomalies in the north are rather different from what is seen in the south as Fig. 3 shows. The overall multiyear monthly mean evolution in both models follows the observed seasonal patterns well. While not shown in Fig. 3, the modelled total ozone in FinROSE is about 40 DUs lower than the TOMS measurements during summer. Furthermore, in some cases during the winter-spring maximum, FinROSE gives over 100 DUs lower total ozone values than TOMS. In UMETRAC the summertime minima are regularly around 100 DUs higher, and the wintertime maximum are around 50 DUs higher than measured. Although the simulated age of air is too short, we may now conclude that the seasonal behaviour in the general transport characteristics is reasonable 

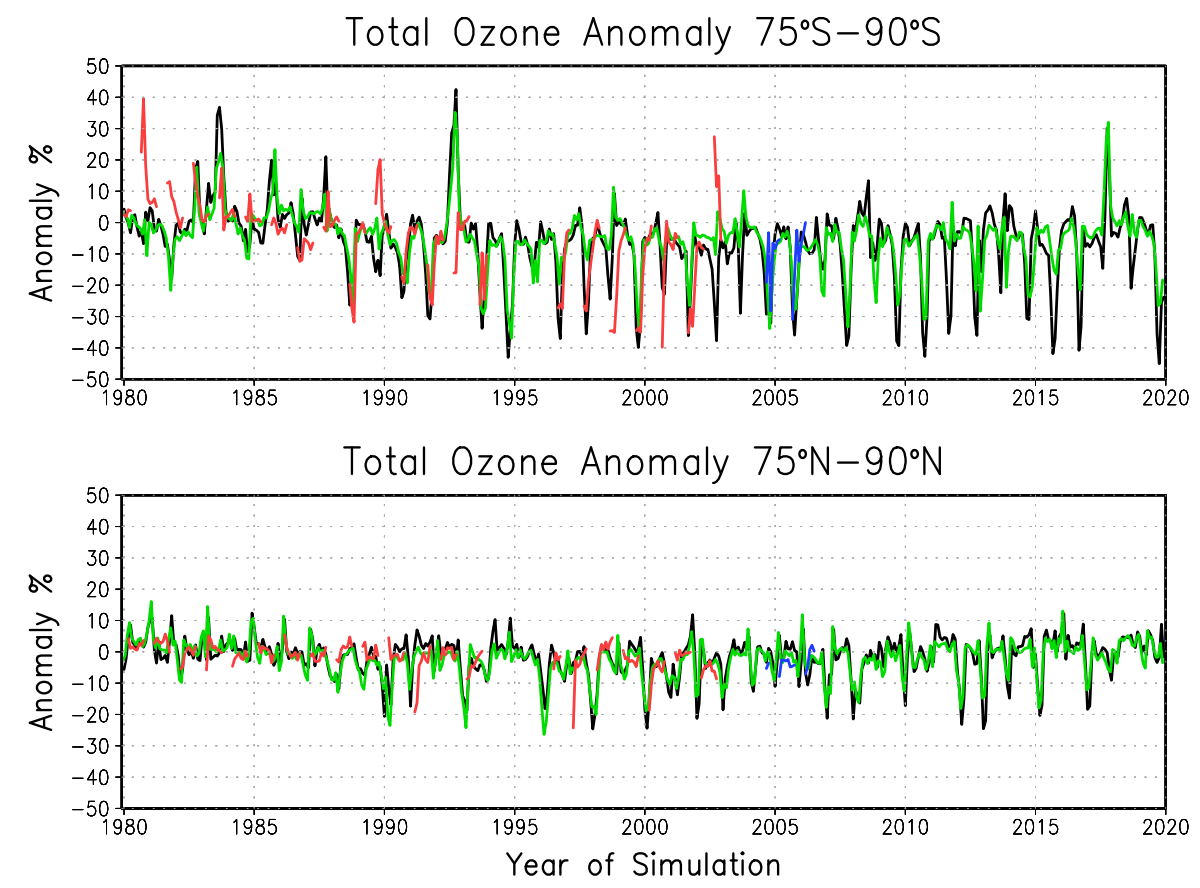

Fig. 3. Comparison of observed total ozone anomalies (from 1980-1989) with the modelled ozone anomalies. Time series are shown as average values within the $75^{\circ} \mathrm{S}$ latitude circle (upper panel) and $75^{\circ} \mathrm{N}$ latitude circle (lower panel). The anomalies in total ozone calculated from FinROSE data are presented by black lines, the UMETRAC anomalies as green lines, and the anomalies derived from the TOMS data by red lines and from OMI by blue lines.

and that there are clear similarities in the modelled interannual and seasonal patterns.

\section{Ozone depletion}

The processes causing ozone depletion require first of all formation of polar stratospheric clouds (i.e. PSCs), enough inorganic chlorine (and possibly other halogens) to be converted to active form, low enough stratospheric temperatures to cause denitrification, and finally, solar radiation to drive the actual ozone loss processes. The distribution of ozone is dependent on both atmospheric transport and chemistry. In order to have an approximate separation of these two main processes, we have formulated a passive ozone tracer, for which only the transport scheme of the model has been applied. The passive ozone tracer is initialized twice every year, on 1st of June, and on 1st of December using the regular model ozone.

Time series of anomalies (from the 1980-1989 mean) in total nitrogen $\left(\mathrm{NO}_{y}\right)$ and water vapour $\left(\mathrm{H}_{2} \mathrm{O}\right)$, the evolution of chlorine activation (i.e. $\mathrm{ClO}_{\mathrm{X}} / \mathrm{Cl}_{\mathrm{X}}$ ), and the difference between the passive ozone tracer $\left(\right.$ Tracer- $\left.\mathrm{O}_{3}\right)$ and model ozone are shown in Fig. 4 for the whole 40-year time series together with the PSC exposure times (for types I and II). All values are based on monthly mean values within $75-90^{\circ} \mathrm{S}$, averaged over the vertical column from 146 to $31 \mathrm{hPa}$ (i.e. between ap- proximately 14 and $24 \mathrm{~km}$ ). The time series show how some major processes are simulated in the model. Significant chlorine activation occurs during every austral winter-spring season of this 40 year time series. The model simulates well the major chlorine activation, which occurs soon after the start of austral polar night. Chlorine activation starts as soon as the type-I PSCs appear. At the same time the level of total nitrogen, expressed by $\mathrm{NO}_{\mathrm{y}}$, starts to decrease. The actual ozone loss, as seen in Fig. 4 starts as the analysed area becomes sunlit. This is seen as a deviation between the passive ozone tracer and model ozone. As the temperatures gradually increase during the spring and the vortex disappears, the PSCs evaporate and the large-scale ozone depletion is typically over by the end of November.

In the early 1980s the magnitude of the simulated ozone loss was at most between 50 and $60 \%$. After the mid1980s ozone depletion started to increase, frequently indicating losses of more than $80 \%$ between 31 and $146 \mathrm{hPa}$. The fractional chlorine activation (in Fig. 4) was typically slightly larger during the 1980s than during 1990s and later decades. However, the total chlorine loading is lower in the 1980s and the net effect on ozone was low.

The rate of decrease of $\mathrm{NO}_{\mathrm{y}}$, i.e. the rate of denitrification, increases when the temperatures drop below the threshold for formation of ice particles. The relatively large PSC-typeII particles are formed and sedimented, which is seen as a 

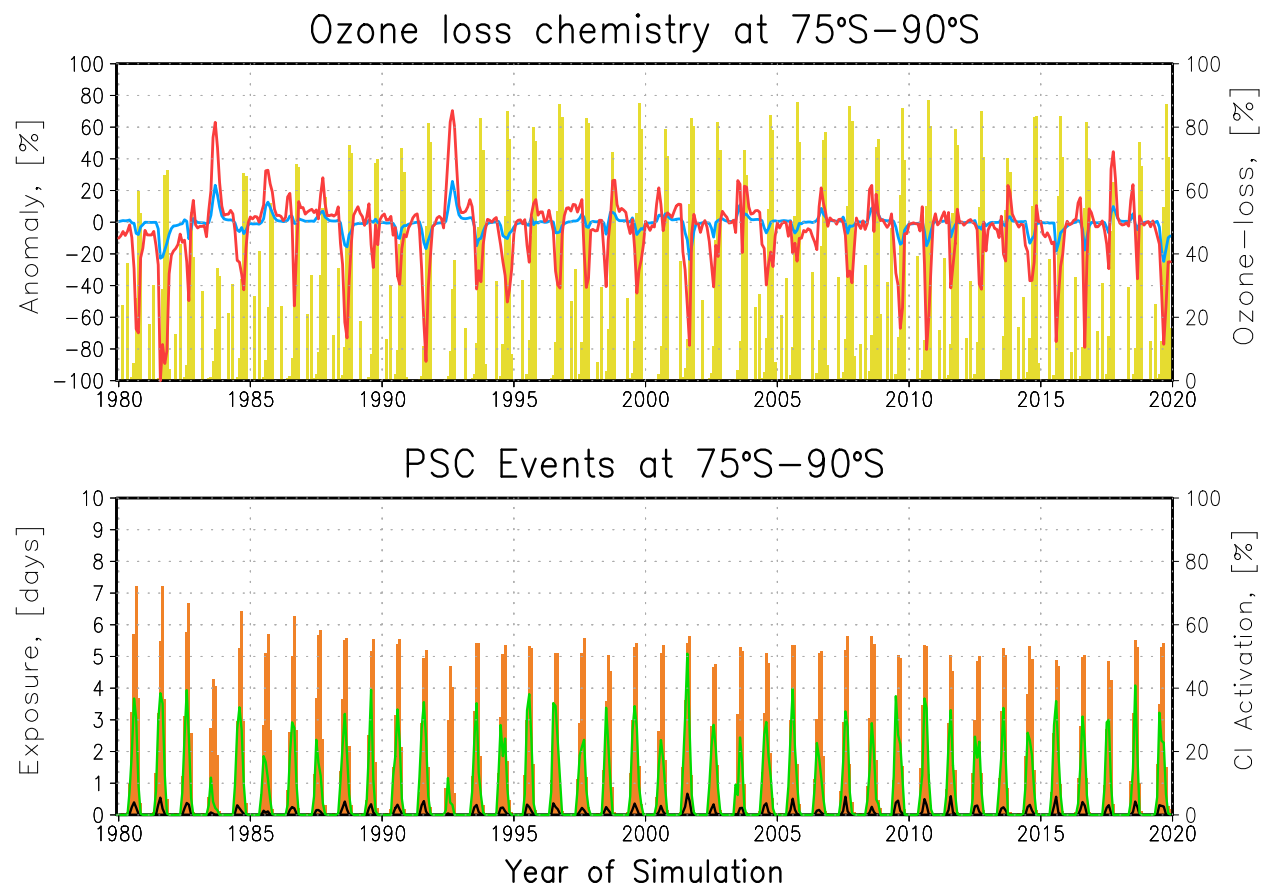

Fig. 4. Simulated evolutions for 1980-2019 of main constituents affecting ozone within $75^{\circ} \mathrm{S}$, and between 146 and $31 \mathrm{hPa}$. In the upper frame the percentage anomalies in total nitrogen is shown by the red line and in water vapour by the blue line. The relative difference between the passive ozone tracer and regular model ozone by yellow bars. In the lower frame the chlorine activation is shown by orange bars, the PSC type-I tracer is given by the green line and the PSC type-II tracer by the black line.

decrease in water vapour and especially in $\mathrm{NO}_{\mathrm{y}}$. The average total nitrogen $\left(\mathrm{NO}_{\mathrm{y}}\right)$ between 146 and $31 \mathrm{hPa}$ shows a significant drop in connection to the occurrence of PSCs of type-II. Since conditions cold enough for the formation of ice particles exist during most of the winter-spring seasons, Fig. 4, the monthly average results do not exhibit any clear signs of significant denitrification caused by rapid sedimentation of large NAT particles (i.e. NAT rocks). However, this does not rule out the possible sedimentation of NAT rocks on a more local and shorter time scale.

Severe denitrification does not take place during every single simulated season. Exceptions are especially the years 1983 and 1992 when the decrease in total nitrogen shown by a positive anomaly, and also the ozone loss is smaller. During these non ozone depletion cases the formation of ice is relatively moderate due to warmer conditions, which can be seen in the PSC exposure in Fig. 4. These warmer conditions may be connected to sudden stratospheric warming events which are known to be very rare in the Southern Hemisphere (see e.g. Shepherd et al., 2005). More likely, they illustrate problems in simulating model dynamics at the edges of the normal distribution.

Figure 5 shows how the two main chemical ozone loss cycles have contributed to the simulated net ozone loss over Antarctica. The relative effect of catalytic ozone loss cycles by active chlorine (i.e. $\mathrm{ClO}_{\mathrm{x}}$ ) is clearly the most significant.
During September these cycles are responsible for about 50 to $80 \%$ of the total ozone loss. The rest of the ozone depletion is due to the second most important catalytic cycle during the ozone hole season, namely the $\mathrm{BrO}-\mathrm{ClO}$ cycle. The coupled $\mathrm{ClO}-\mathrm{BrO}$ destruction of ozone is almost as important as the $\mathrm{ClO}_{\mathrm{x}}$ cycles during August and October. However, it should be kept in mind that the amount of absolute ozone depletion itself is smaller during August as there is only a limited amount of solar radiation available within the analysed area. It is also worth noting that during other times of year, the catalytic cycles of $\mathrm{NO}_{\mathrm{x}}$ (summer), and $\mathrm{HO}_{\mathrm{x}}$ (autumn) are the main contributors to ozone depletion (not shown). However, as seen from Fig. 5 these cycles do not contribute significantly to the chemical depletion of ozone during winter and spring.

Another way to analyse the 40-year time-series is to look at the total inorganic chlorine level in the atmosphere (see Table 1). Keeping in mind that since early 1980s the inorganic chlorine loading increased from about 1.6 to about $3.5 \mathrm{ppb}_{\mathrm{v}}$ in the late $1990 \mathrm{~s}$, and that it is projected to remain above $3 \mathrm{ppb}_{\mathrm{v}}$ until the end of the 40-year simulation period, a conclusion can be made: Chlorine activation, although a regular phenomenon, does not in itself lead to severe ozone depletion. After the winter season the high southern latitude stratosphere becomes sunlit and the active chlorine is rapidly deactivated if $\mathrm{NO}_{2}$ is present. This means that the amount 

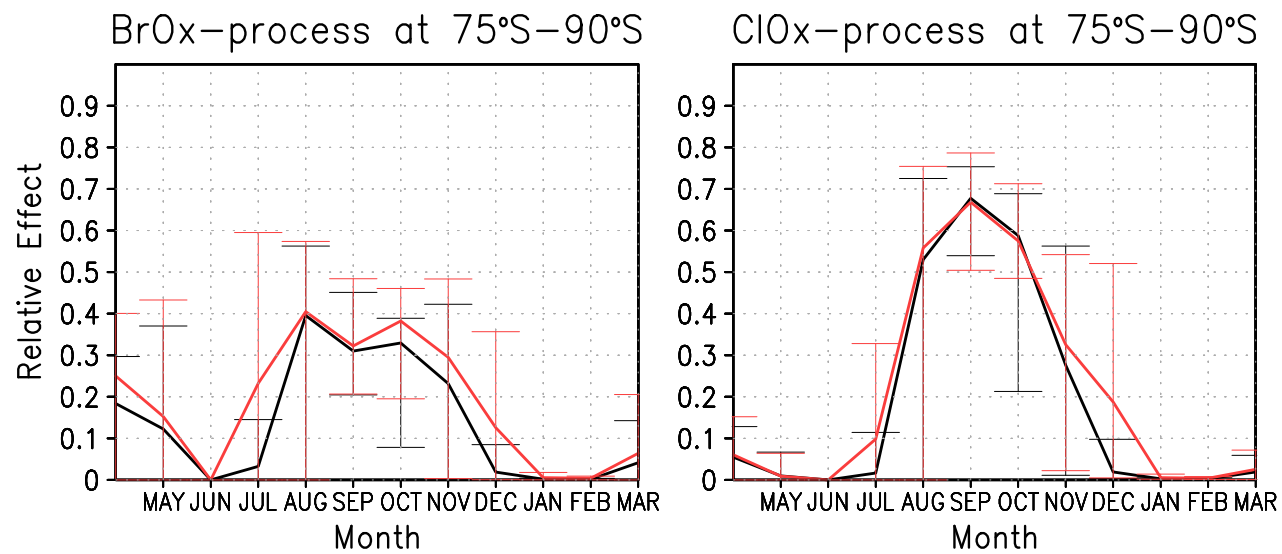

Fig. 5. A climatology showing the relative portions of the ozone loss chemistry due to the two main catalytic ozone loss cycles in FinROSE. The left panel shows the effect of the $\mathrm{ClO}_{\mathrm{x}}$ processing and the right panel shows the effect of combined $\mathrm{BrO}_{\mathrm{x}}-\mathrm{ClO}_{\mathrm{x}}$ chemistry. The past period (1980-1999) is indicated with black lines and the future period (2000-2019) with red lines. The errorbars show the minimum and maximum portions during each month. The values are averaged within the $75^{\circ} \mathrm{S}$ latitude, and between $146 \mathrm{and} 31 \mathrm{hPa}$.

of inorganic chlorine controls the potential severity of ozone depletion, and the occurrence and magnitude of PSCs and denitrification affects how long ozone depletion is prolonged in the spring.

The time series in Figs. 3 and 4 show that the increase in inorganic chlorine has made the ozone depletions more severe since the beginning of 1980s. The level of ozone depletion reached during the latter part of the 1990s seems to continue also during the future period. The two main factors are in place (i.e. the chlorine activation, and denitrification) throughout the whole 40-year simulation, while during the early years the actual levels of inorganic chlorine were lower, and therefore the ozone depletion was less severe. However, it is important to note that even with inorganic chlorine levels below $2 \mathrm{ppb}_{\mathrm{v}}$, large-scale ozone destruction may occur, provided that the temperatures are low enough for extended periods of time leading to e.g. denitrification.

The situation in the winter and springtime northern highlatitude stratosphere is far less favourable for PSC formation than in the south, as sufficiently low temperatures do not occur regularly. Time series of anomalies (from the 1980 1989 mean) in total nitrogen $\left(\mathrm{NO}_{\mathrm{y}}\right)$ and water vapour $\left(\mathrm{H}_{2} \mathrm{O}\right)$, the evolution of chlorine activation (i.e. $\mathrm{ClO}_{\mathrm{x}} / \mathrm{Cl}_{\mathrm{x}}$ ), and the difference between the passive ozone tracer $\left(\right.$ Tracer- $\left.\mathrm{O}_{3}\right)$ and model ozone are shown in Fig. 6 for the whole 40-year time series together with the PSC exposure times (for types I and II). All values are based on monthly mean values within 75 $90^{\circ} \mathrm{N}$, averaged over the vertical column from 146 to $31 \mathrm{hPa}$ (i.e. between approximately 14 and $24 \mathrm{~km}$ ). As can be seen, these results differ from the Antarctic ones. While $\mathrm{NO}_{\mathrm{y}}$ seems to exhibit some drops during the course of the simulation, the water vapour distribution is stable.

Interestingly, it seems that even on this average perspective chlorine activation of around 20 to $30 \%$ takes place during almost every winter/spring. The level of chlorine activation is clearly connected with the average existence of type-I PSCs, while in this averaged analysis no signs of type-II PSCs are found. The ozone loss exhibits no clear trend, except perhaps the increase during the first half of the 1980s. The cases of higher chlorine activations clearly coincide with the weak, but obvious, denitrifications and in turn with the ozone losses. It is quite clear that the low stratospheric temperatures provide the conditions for ozone depletion. Therefore, if the stratospheric temperatures would decrease as a result of the enhanced greenhouse effect, the probability for significant ozone loss may increase in the northern hemispheric high-latitudes.

In general, between $75^{\circ} \mathrm{N}$ and $90^{\circ} \mathrm{N}$, the total nitrogen does not exhibit as large a decrease as it does over Antarctica. This result is expected, as the temperatures are not low enough for ice-cloud formation. Since PSC type-II clouds are uncommon in the northern polar stratosphere, no extensive ozone depletion occurs. However, during some years stronger denitrification occurs, as the negative anomalies (from the 1980-1989 mean) in $\mathrm{NO}_{\mathrm{y}}$ reach values of about 50 to $60 \%$. A closer look at the PSC-tracers also indicates that while there are no ice-form PSCs, type-I PSCs are seen during most of the winters since the mid 1980s.

Another interesting feature in these figures emerges if the behaviour of total nitrogen, water vapour, and the existence of ice-clouds are compared with each other. It seems that while there are no type-II PSCs, the NAT PSCs coincide with the stronger denitrifications. A logical conclusion is that the NAT particles have grown to sizes where significant sedimentation is possible. Denitrification occurs, but these low temperatures are not persistent enough for large scale denitrifications. Nevertheless, during the most prominent years (e.g. 2000 or 2013) the drop in total nitrogen over the Arctic is calculated to be about $40 \%$. 

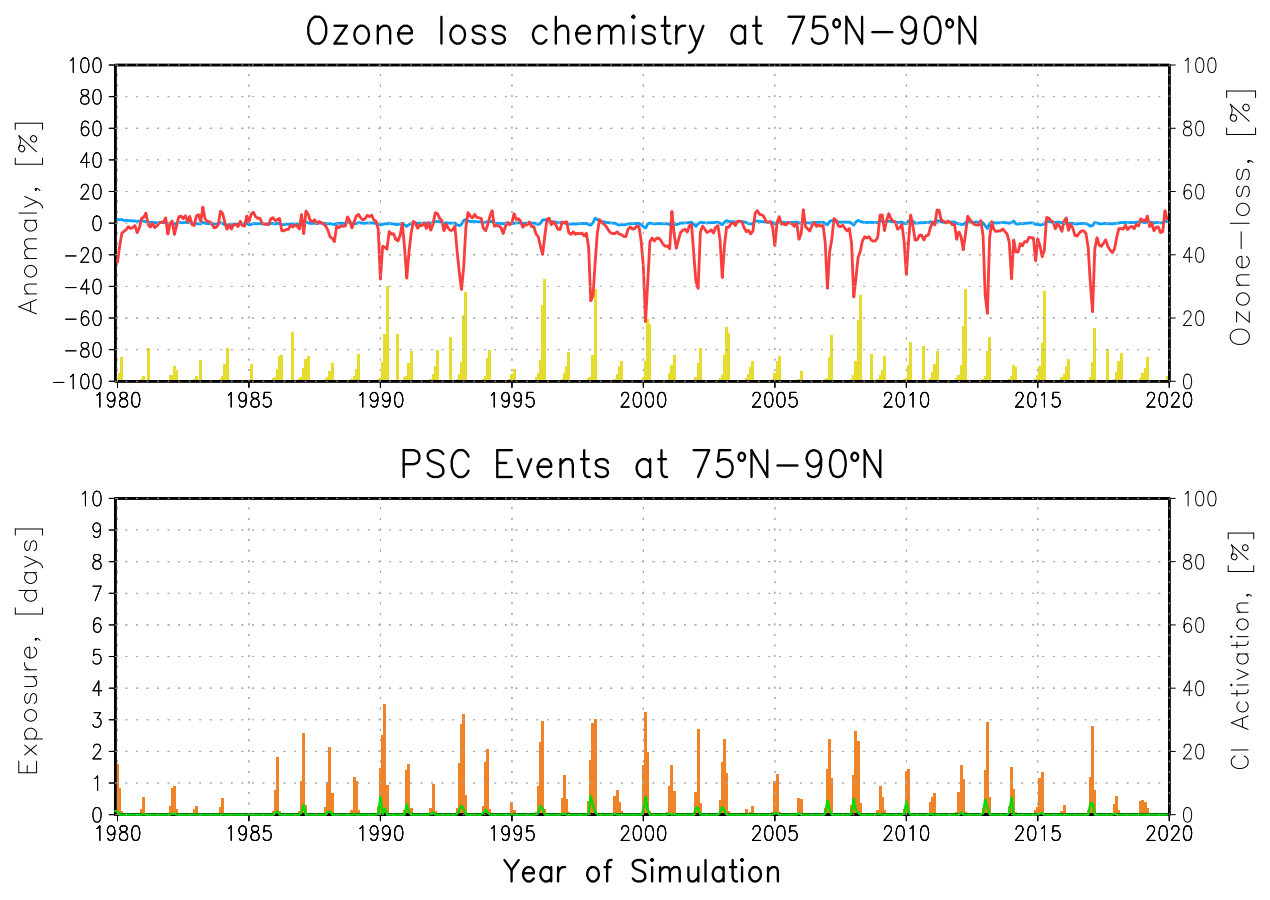

Fig. 6. Simulated evolutions for 1980-2019 of main constituents affecting ozone within $75^{\circ} \mathrm{N}$, and between 146 and $31 \mathrm{hPa}$. In the upper frame the percentage anomalies in total nitrogen is shown by the red line and in water vapour by the blue line. The relative difference between the passive ozone tracer and regular model ozone by yellow bars. In the lower frame the chlorine activation is shown by orange bars, the PSC type-I tracer is given by the green line and the PSC type-II tracer by the black line.

Figure 7 shows a climatology of how the different ozone loss processes have contributed to the net ozone loss in the north. During the northern hemispheric winter and spring the catalytic ozone loss cycles by active chlorine and bromine are almost equally significant as they are responsible for about 30 to $40 \%$ each of the total ozone loss. During the first half of the 1980s, processes other than chlorine destruction, or coupled bromine-chlorine destruction were dominant, i.e. the $\mathrm{NO}_{\mathrm{x}}$-chemistry had a more significant role until the early 1990s (not shown). However, the absolute levels of ozone depletion were lower than after the mid 1980s. Furthermore, the previously shown timeseries (Fig. 6) suggests that during years with more significant ozone depletion, destruction by $\mathrm{ClO}_{\mathrm{x}}$ is the most important process.

In the Arctic stratosphere denitrification is clearly weaker than in the Antarctic, and therefore the net ozone depletion is also weaker in the 40-year simulation. However, as already stated for the Antarctic stratosphere, even a chlorine loading below $2 \mathrm{ppb}_{\mathrm{v}}$ may lead to significant large scale ozone depletion if conditions for chlorine activation and denitrification prevail for long enough time periods. Therefore, the possible cooling of the Arctic stratosphere may give rise to more severe ozone depletion.

\section{Ozone changes and trends}

Figure 8 can be taken as a starting point for the analysis of the high latitude ozone changes. Ozone changes in the simulated data are shown as the difference between the climatology of 1980-1984 and the respective climatology of 1995-1999 (i.e. near past change). The near future change is shown as a difference between the ozone climatology of 1995-1999 and the climatology of 2015-2019. Figure 8 shows these differences in the mixing ratio. The past period difference shows a decrease in the ozone mixing ratios throughout the whole stratosphere. This difference has its maximum in the Antarctic polar stratosphere, being over $300 \mathrm{ppb}_{\mathrm{v}}$ around $50 \mathrm{hPa}$. While in the north the respective stratospheric decrease is about 100 to $150 \mathrm{ppb}_{\mathrm{v}}$, depending on the altitude. During the future period, the model gives a slight increase of $50 \mathrm{ppb}_{\mathrm{v}}$ near $50 \mathrm{hPa}$, over the southern polar areas, and a similar increase in the upper stratosphere. Over the northern polar areas an increase of the order of $50 \mathrm{ppb}_{\mathrm{v}}$ is seen throughout the whole stratosphere above $100 \mathrm{hPa}$. The results shown here will be discussed further below where the statistical significance of these changes will be assessed using trend analysis.

Figure 9 shows the latitudinal distribution of average annual trend estimates from the FinROSE, TOMS (version 8) and UMETRAC total ozone for the past period (1980 to 1999). The trend estimates of both models for the near future 

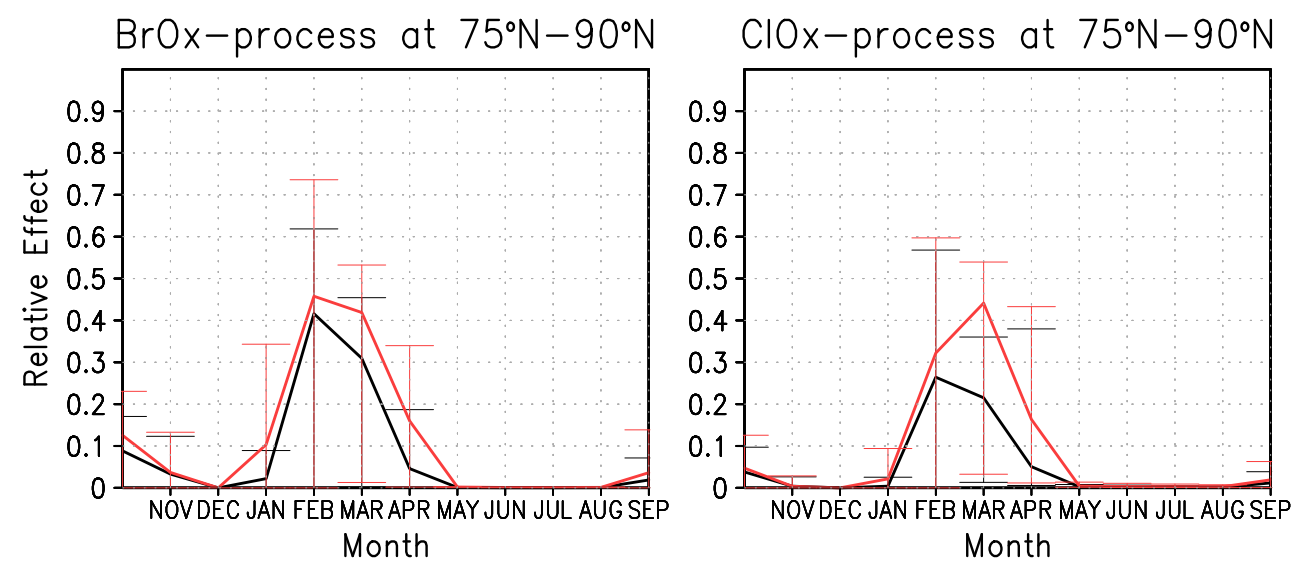

Fig. 7. A climatology showing the relative portions of the ozone loss chemistry due to the two main catalytic ozone loss cycles in FinROSE. The left panel shows the effect of the $\mathrm{ClO}_{\mathrm{x}}$ processing and the right panel shows the effect of combined $\mathrm{BrO}_{\mathrm{x}}-\mathrm{ClO}_{\mathrm{x}}$ chemistry. The past period (1980-1999) is indicated with black lines and the future period (2000-2019) with red lines. The errorbars show the minimum and maximum portions during each month. The values are averaged within the $75^{\circ} \mathrm{N}$ latitude, and between $146 \mathrm{and} 31 \mathrm{hPa}$.

period (2000-2019) are also shown. The trend estimates are calculated applying a standard linear regression to the monthly mean values. The trend errors, based on the Student's T-test, are given for the $95 \%$ significance level. The overall agreement with measurements is good and both models give similar trend estimates as obtained from the TOMS measurements.

For the past period, both actual values and uncertainty intervals of the FinROSE trends behave similarly as the TOMS trends. In the vicinity of $60^{\circ} \mathrm{S}$ the decreasing annual average trend from FinROSE is only slightly less than the TOMSderived trend. In the case of UMETRAC, the magnitude of the southern trends is somewhat smaller than the corresponding FinROSE trends, and the trend errors exhibit somewhat narrower error ranges.

Both models give large, statistically significant negative trends over the high polar latitudes. Over Antarctica the trend in the FinROSE data is almost $-8 \% /$ decade and in the UMETRAC data the trend is about $-6 \%$ /decade. Over the northern polar areas, FinROSE gives a trend of about $-3.5 \% /$ decade, and UMETRAC about $-5.5 \% /$ decade. The trends in polar ozone are well in line with the trend estimates shown by WMO (2003, Chapter 4, Figs. 4-31) Hadjinicolaou et al. (2002) or Fioletov et al. (2002).

The average annual trend estimates for the future period (in Fig. 9) are similar for both models over the high southern latitudes. Both models exhibit small but statistically insignificant positive trends of 2 to $3 \%$ per decade. Over the northern polar areas the results of the two models are almost the same. The UMETRAC trend estimates give a positive trend of about 3\%/decade, which is significant at the $95 \%$ confidence level. FinROSE gives nearly the same trend with a somewhat larger error range and the trend is also significant at the 95\% level. From an annual average perspective

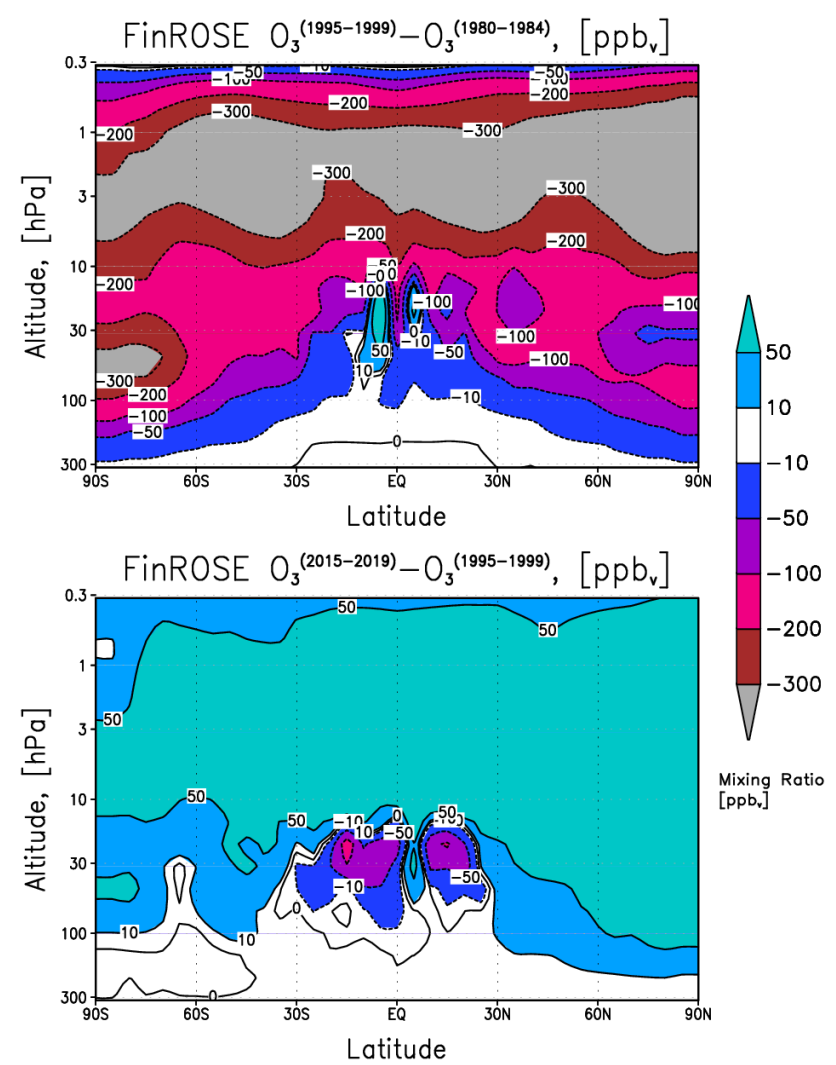

Fig. 8. Ozone changes in average annual zonal distributions. Top panel gives the change between 1980-1985 and 1995-1999. Lower panel shows the difference between 1995-1999 and 2015-2019. Values are shown as mixing ratios. 

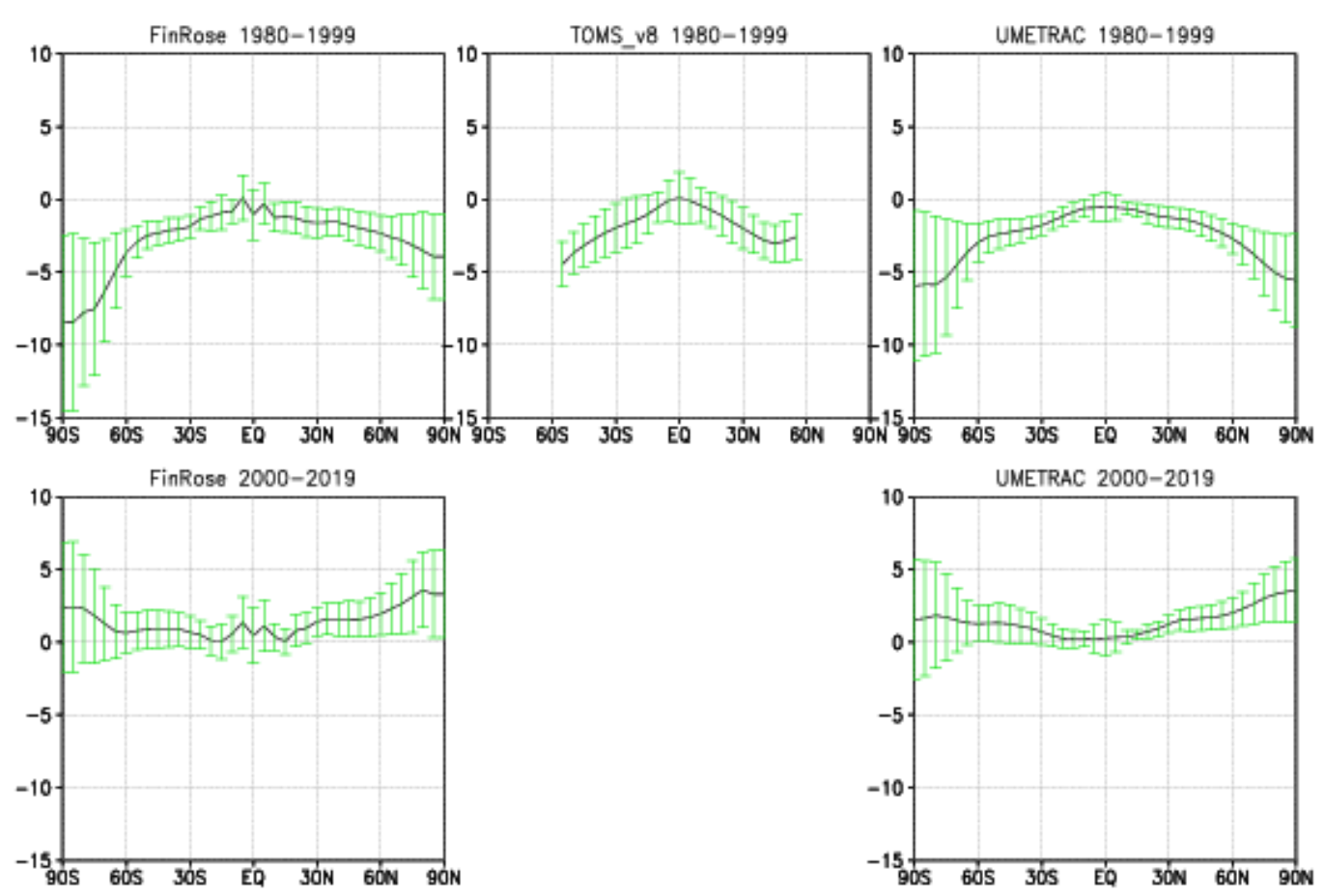

Fig. 9. Annually averaged total ozone trends [\%/decade]. The errorbars indicate the $95 \%$ confidence intervals, calculated using the Student's T-test.

the results from both models suggest that a small increase in total ozone may take place over high southern latitudes by 2019 . However, the statistical significance is low implying that the ozone depletion may remain on a similar level to what was seen in the 1990s. Over the northern polar areas, on an annual average basis, a statistically significant positive trend is simulated, which could be a sign of a start of ozone recovery. These results are in line with those presented in Fig. 8.

Figure 10 shows the latitudinal distributions of seasonal total ozone trend estimates of FinROSE and TOMS for the past period and FinROSE for the future period. As for the annual average trend estimates, the seasonal trend estimates from FinROSE are also in good or reasonable agreement with the TOMS trends. During the northern winter months (i.e. December, January, and February) over northern high latitudes the modelled trends are between -5 and $-8 \% /$ decade, being significantly different from zero at the $95 \%$ confidence level. During the spring months (March through May) at high northern latitudes, the model agrees reasonably well with the measured trends. While TOMS gives a significant negative trend of around $-7 \% /$ decade, FinROSE reproduces a trend of around $-5 \% /$ decade, which agrees with the observations at the $95 \%$ confidence level.

The southern high latitude trends, shown in Fig. 10 left and middle panels follow the observation based trends. During the austral winter (June-August), the model reproduces the observed trends well. During the austral spring (SeptemberNovember), the most visible feature is the large, statistically significant (at the 95\% confidence level) negative trend of total ozone. At about $80^{\circ} \mathrm{S}$, the TOMS and FinROSE trend estimates agree with a trend of about $-18 \% /$ decade. FinROSEs trend errors are in good agreement with the TOMS trend errors, suggesting that the interannual variability simulated by FinROSE is also of the same order. It is interesting to note that a typical problem of model simulations over the northern mid-latitudes is also evident here. The northern hemisphere mid-latitude negative ozone trend, which peaks between $45-50^{\circ} \mathrm{N}$ and then reduces toward $60^{\circ} \mathrm{N}$ (e.g. Hadjinicolaou et al., 2005) is not well simulated.

In Fig. 10 (right panel) the seasonal trend estimates for latitudinal total ozone behaviour in the near future (2000-2019) are shown. It can be seen that the winter and spring total ozone will increase over the poles. For the Arctic winterspring seasons this increase is around 3 to $5 \% /$ decade, and in the south for the austral winter-spring, the increase is about 2 to $3 \% / d e c a d e$. The FinROSE results indicate that the negative ozone trends are levelling off during the near future. Since the positive trends in winter and spring high latitudes, calculated from the FinROSE results, are not significant, we can conclude (supported by e.g. Weatherhead et al., 2000; Austin and Butchart, 2003; Weatherhead and 

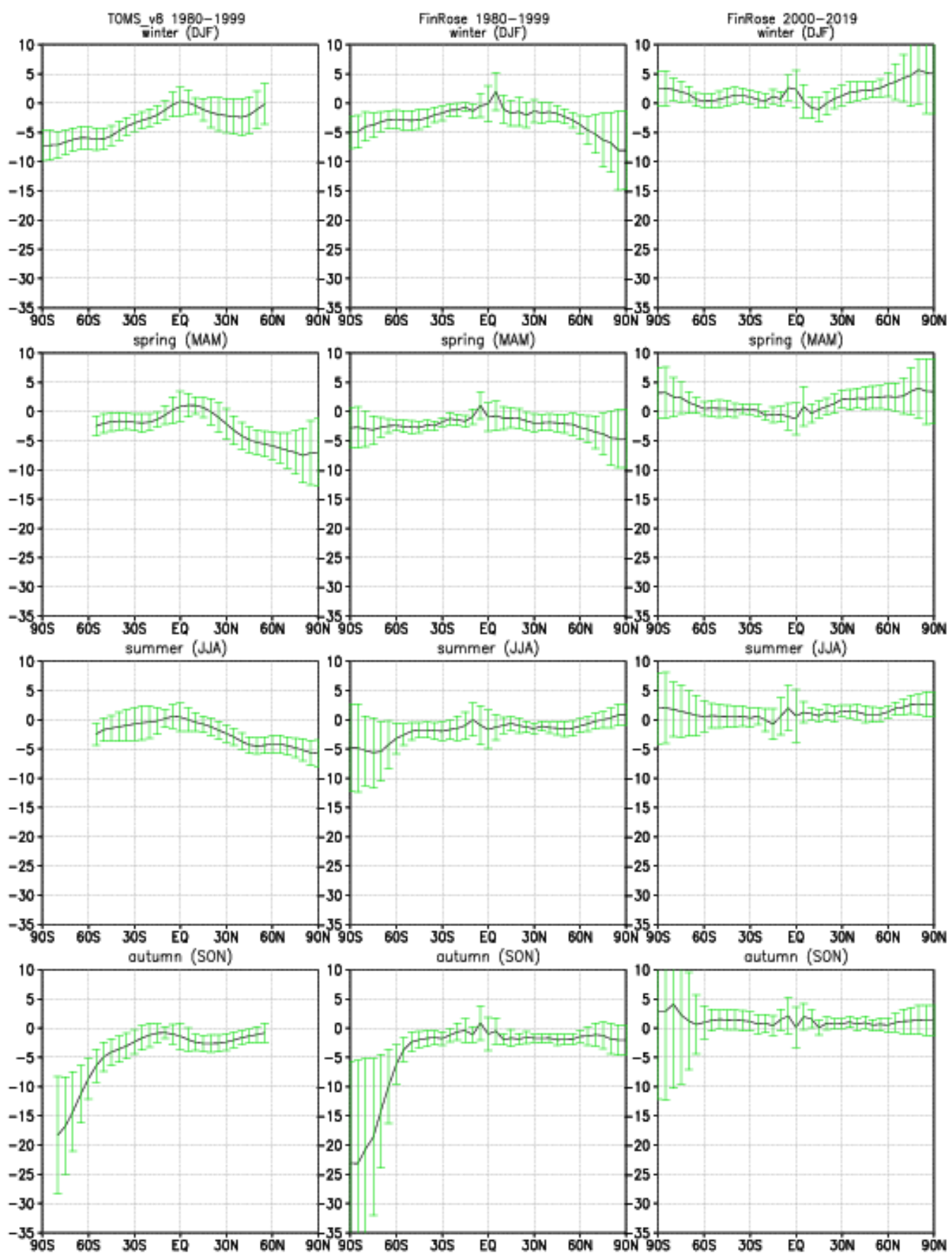

Fig. 10. Seasonally averaged total ozone trends [\%/decade] of TOMS observations for the period 1980-1999 and of FinROSE for period 1980-1999 and 2000-2019. The error bars indicate the 95\% confidence intervals, calculated using the Student's T-test.

Andersen, 2006) that no unambiguous recovery of the ozone is likely to be seen before 2020. The results of Austin and Butchart (2003), as well as those in Austin et al. (2003b) also suggested that the turnover of ozone trends would start in about 2005. The results presented here support those conclusions.
Figure 11 shows vertical cross-sections of the simulated seasonal trends in FinROSE for the past period, focusing on high latitudes. In the past negative trends between 250 and $10 \mathrm{hPa}$ are typical during all seasons. During the northern hemispheric winter, the statistically most significant (95\% confidence, or more) trends are between -5 and 

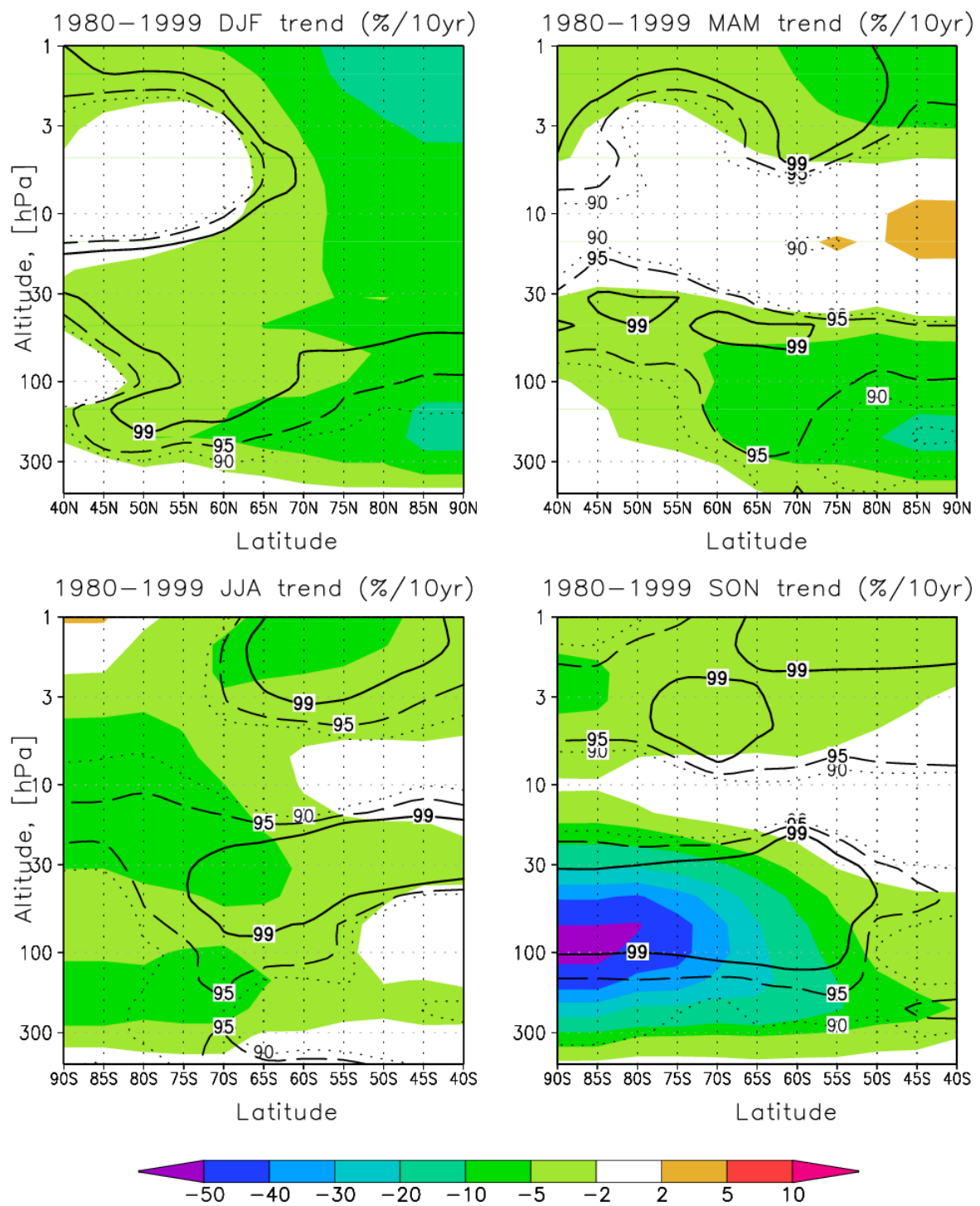

Fig. 11. Vertical distributions of the seasonal ozone concentration trends [\%/decade] for the past period (1980-1999). The significance levels are indicated with dotted black lines for $90 \%$ significance, with dashed for $95 \%$ significance, and with solid black line for $99 \%$ significance.

$-10 \% /$ decade above $100 \mathrm{hPa}$, and north of the $65^{\circ} \mathrm{N}$ latitude. The maximum trend in the northern hemispheric winter is, however, located between 250 and $150 \mathrm{hPa}$, being about $-15 \% /$ decade (without statistical significance). This large negative trend is associated with trends in tropopause height, and is further discussed below. In the northern hemispheric spring the decreasing trend in the lower stratosphere above $40 \mathrm{hPa}$ disappears while the negative trend below $40 \mathrm{hPa}$ stays negative. Similarly to the winter trend estimates, a statistically significant trend between -5 and $-10 \% /$ decade is found between 150 and $50 \mathrm{hPa}$, while the maximum negative trend of about $-15 \% /$ decade is located between 250 and $150 \mathrm{hPa}$. In the spring, this upper tropospheric to lower stratospheric trend is significant at the $90 \%$ level north of $75^{\circ} \mathrm{N}$.
Over the southern hemispheric high latitudes (in Fig. 11) the winter trend estimates are somewhat different. While negative trends are typical over the whole domain, the statistical significance of the negative ozone trends south of $75^{\circ} \mathrm{S}$, and below $10 \mathrm{hPa}$, is weak. At the $95 \%$ significance level a trend between -5 and $-10 \% /$ decade is found only between 25 and $10 \mathrm{hPa}$, and the statistically most significant trends are seen south of $75^{\circ} \mathrm{S}$ around $25 \mathrm{hPa}$. During the Antarctic spring, ozone is depleted with estimated trends more than $-40 \% /$ decade south of the $75^{\circ} \mathrm{S}$ latitude between 150 and $50 \mathrm{hPa}$. The estimated trends are also significantly different from zero at the $99 \%$ level, and are related to the increasing halogen amounts (Table 1). These seasonal trend estimates are also in agreement with the observed trend estimates presented by Randel and Wu (1999). 

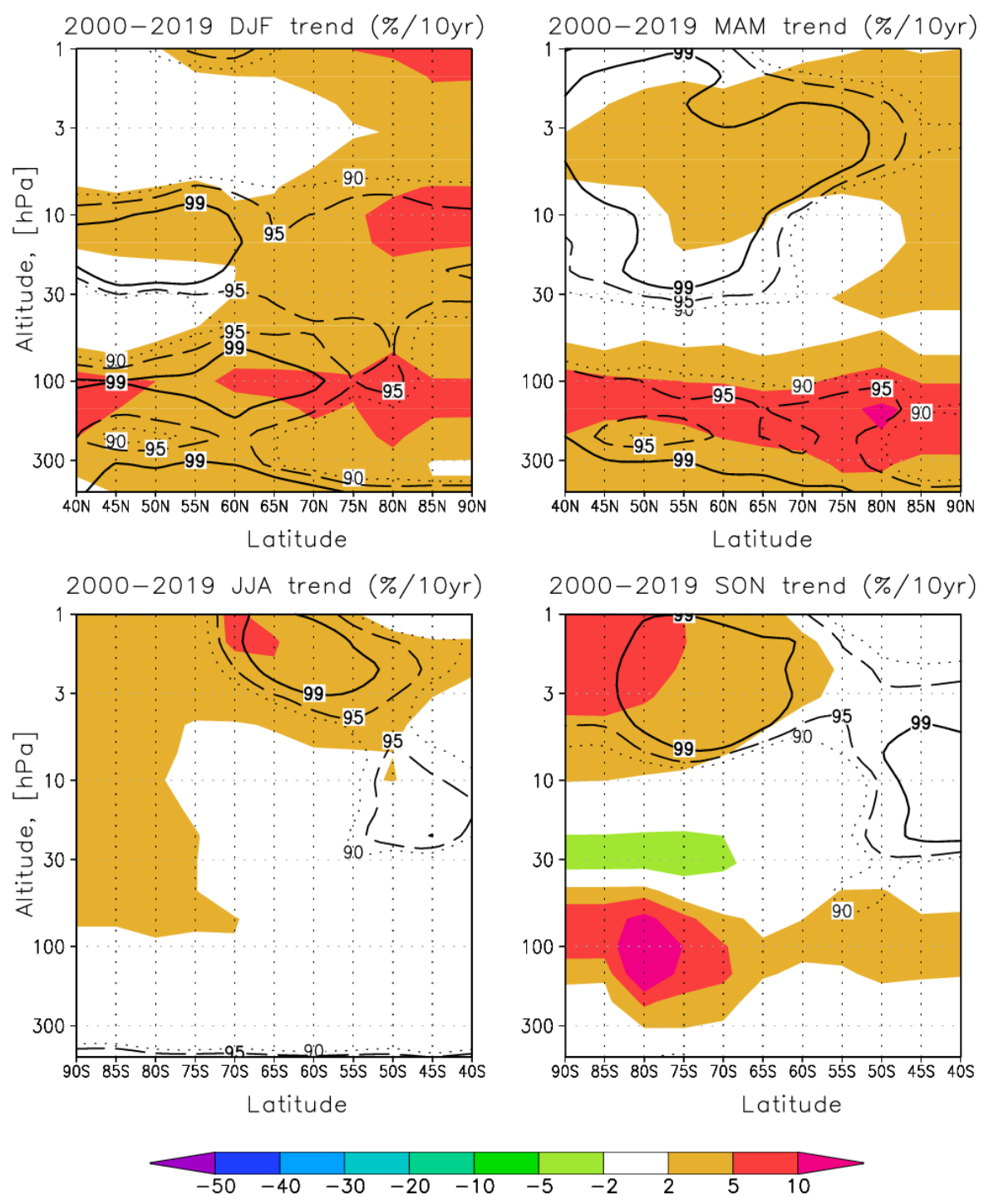

Fig. 12. Vertical distributions of the seasonal ozone concentration trends [\%/decade] for the future period (2000-2019). The significance levels are indicated with dotted black lines for $90 \%$ significance, with dashed for $95 \%$ significance, and with solid black line for $99 \%$ significance.

Simulated trends for the future period are shown in Fig. 12. A very general conclusion of the northern polar stratospheric ozone trends is that they are slightly positive, but statistically not significant within the polar area. The same is true in the case of southern hemispheric wintertime trends (i.e. June to August). During the austral spring a small negative trend of ozone is found close to $30 \mathrm{hPa}$ south of $70^{\circ} \mathrm{S}$, although without statistical significance. According to WMO (2003) the decrease in the atmospheric chlorine loading will lead to a gradual recovery of the stratospheric ozone over the next 50 years. No clear signal of the start of the recovery of ozone is seen during the first two decades of the 21 st century. However, the results from FinROSE do show that the ozone levels off during the last two decades of the simulation. The stratospheric cooling due to the climate change has a potential for enhancing the polar ozone depletion. However, based on the analyses of the ozone trends alone, it is not straightforward to say, whether this mechanism is seen in these results or not.

The negative ozone trend close to the tropopause in high northern latitudes during winter and spring, shown in Fig. 11 is in line with a number of recent studies (see e.g. WMO, 2003). The observed dependence of the column ozone on the tropopause height is well documented, although the level of understanding is still somewhat limited. In general, the observations have shown that the northern hemispheric tropopause at mid- and high-latitudes have risen 
during the past few decades, which imply decreases in total ozone. Austin et al. (2003a) have shown that in the driver model (i.e. UMETRAC), a statistically significant decrease in tropopause pressures is exhibited over a wide range of latitudes. Furthermore, over the mid-latitudes this negative trend is about $1 \mathrm{hPa} / \mathrm{decade}$, which in turn is in line with observations and other model changes (Santer et al., 2003). In WMO (2003) it was concluded that these trends are not due to the changes in stratospheric ozone, and thus radiatively driven, but due to the changes in tropospheric circulation. As a conclusion, it may be stated that the FinROSE simulation also exhibits this observed connection between the tropopause height and ozone.

\section{Discussion}

The quality of CTM studies is very much dependent on the transport characteristics, the quality of the driver fields, as well as on the chemistry scheme of the CTM. With respect to this study, the uncertainties associated with the CCM have been discussed by Austin et al. (2003b). The shortcomings in the realized Brewer-Dobson circulation, and the large natural variability of the northern polar vortex, increased the uncertainty of the trend analyses in this study. The problems in the age of air distribution and the Brewer-Dobson circulation, are well-known features of CTMs (Hall et al., 1999).

Every model produces its own aeronomy, and its own balances between radiation driven processes, dynamically driven processes, and chemistry driven processes. This means that in the case of dynamically-driven atmospheric processes, the patterns reproduced by FinROSE follow those in the driver simulation, which in turn are dependent on the radiation couplings or used WMGHG projections in the $\mathrm{CCM}$ itself. In the case of chemistry-driven processes, like the springtime Antarctic ozone hole, the FinROSE model is capable of making a more independent representation. In general, the results presented here indicate that the ozone evolution is more predictable in the winter-spring Antarctic stratosphere than in the Arctic stratosphere where the natural interannual variability is greater.

Since the analyses in this study are based on average quantities (i.e. zonal averages, monthly means etc.), we have not discussed all the fine-scale features that the simulation contains. The inclusion of the effects caused by large NAT particles (i.e. sedimentation and denitrification) clearly have an effect on the results exhibited in this study, as the moderate Arctic denitrifications are being reproduced in the absence of ice particles. These results suggest, in line with other studies (e.g. WMO, 2003), that the denitrification caused by gravitational settling of ice particles is not causing denitrifications over the Arctic. While there was evidence of denitrifications due to large NAT PSC sedimentation, the threshold for the ice-formation was not crossed.
From the Antarctic perspective, as the temperatures below the frostpoint are observed on annual basis during winter, the process of PSC sedimentation is relatively straightforward. However, as shown by Fahey et al. (2001), and further studied by Carslaw (2002), under persistent conditions the NATtype PSCs may also grow as large as 10 to $20 \mu \mathrm{m}$, and therefore cause significant denitrifications due to sedimentation. This phenomena can be of great importance in the wintertime northern polar stratosphere where temperatures below ice frostpoint are uncommon. According to WMO (2003), the largest uncertainties in stratospheric model studies of ozone depletion are due to the unrealistic representation of denitrification processes. In order to have a more realistic description, especially in the Arctic, the 40-year simulation presented in this study takes into account denitrification effects resulting from the growing of the NAT particles to sizes where sedimentation may become truly effective. However, since this work is based on a single simulation, and focuses on the analysis of climate-scale average quantities, it is not straightforward to make conclusions on the effect of the more detailed treatment of denitrification.

In the Arctic stratosphere, chlorine activation is an annual phenomenon. However, since the conditions in the Arctic polar vortex are less severe than in the Antarctic, no large scale Antarctic-like ozone depletion is seen in the simulation before the end of 2019. It is also possible that more local ozone perturbations may cause elevated levels of UV over the populated northern hemisphere high-latitude areas if the ozone depletion affects the ozone distributions during the following summer as well. This matter has recently been addressed by Fioletov et al. (2005). Recently, quantitative relations between the stratospheric temperatures and the Arctic springtime ozone losses were found and discussed by Rex et al. (2004). Based on the observations, it was shown that in the stratosphere, for each Kelvin cooled, a 15 DU total column ozone reduction is realized. Further significant depletion could occur if the temperatures in the Arctic reach ice-formation temperatures on larger scales before the chlorine loading has reduced below $2 \mathrm{ppb}_{\mathrm{v}}$. Here the early 1980s ozone depletion events are important references. As was noted before, even chlorine levels below $2.1 \mathrm{ppb}_{\mathrm{v}}$ may cause large-scale ozone depletion. Whether the regulations in the Montreal protocol (UNEP , 2000) are enough in a colder stratosphere remains unanswered in this work. The level of chlorine remains above $3 \mathrm{ppb}_{\mathrm{v}}$ during the timeframe of this study (i.e. 1980-2019), therefore a longer simulation timeframe would be needed. The Antarctic ozone depletions are expected to continue as severe as they are at present until the end of 2019.

\section{Summary and conclusions}

Off-line Chemical Transport Models (CTMs) driven by externally provided wind and temperature fields are very 
useful for the studies of atmospheric processes on various timescales. The main purpose of this study was to use the winds and temperatures resulting from a 40-year coupled chemistry climate model simulation, to drive the FinROSE chemistry transport model for the study of the past and future behaviour of the ozone layer. Global CTMs have mostly been used for multi-year simulations of the stratosphere using observational based meteorologies (e.g. analyses of numerical weather prediction models, like the ECMWF model). The results presented and discussed in this paper should be considered, first of all, as a proof for the applicability of the combined CTM-CCM approach itself in climate scale studies, as well as a documentation of the 40-year simulation. The advantages of using the off-line chemistry transport approach with externally specified winds and temperatures, are abundantly cost-beneficial. More effort can be put to the representativeness of the chemistry solvers and output diagnostics. Therefore, the CTMs provide an affordable platform for the studies of individual atmospheric processes and add value to the chemistry coupled climate model integrations. Our general conclusion is therefore that this approach provides an efficient tool with which to explore the long term chemistry of the stratosphere both during the past and for the future.

In order study the effect of stratospheric cooling on ozone depletion we showed how the average polar concentrations of stratospheric ozone, and processes leading to the high latitude ozone destruction evolved in our simulation during the past (1980-1999) and near future (2000-2019) periods. We also compared our results with measurements, and performed a trend analysis for the past and future periods. Summarizing the overall results of the 40-year CTM simulation we may state that the simulated patterns in the near past agreed well with the observed patterns and trend estimates opening the way for the conclusions about the future. The results of this study suggest that the extent of seasonal ozone depletion over both northern and southern high-latitudes are near a maximum and that while climate change might cool the lower stratosphere, the cooling in this simulation did not accelerate high latitude ozone depletion significantly. The recovery of seasonal high latitude ozone losses is not to take place for the next 15 years, emphasizing the need for longer model integrations for the predictions of ozone recovery.

Acknowledgements. The authors are grateful to the Ozone Processing Team at the NASA Goddard Space Flight Center for the TOMS V8 column ozone, and to the OMI groups at FMI, KNMI and NASA for the OMI column ozone data. The authors wish to thank Prof. G. Brasseur for providing the original model code and valuable guidance. The funding received through the EU projects EuroSPICE (EVK2-CT-1999-00014) and CANDIDOZ (EVK2-CT-2001-00133) is gratefully acknowledged. We are also thankful for the funding received from the Academy of Finland through the projects FAUVOR II and FARPOCC.

Edited by: M. Dameris

\section{References}

Austin, J.: A Three-Dimensional Coupled Chemistry-Climate Model Simulation of Past Stratospheric Trends, J. Atmos. Sci., 59, 2, 218-232, 2002.

Austin, J. and Butchart N.: Coupled chemistry-climate model simulations for the period 1980 to 2020: Ozone depletion and the start of ozone recovery, Q. J. Roy. Meteorol. Soc., 129, 32253249, 2003.

Austin, J., Butchart, N., Claud, C.,, Cagnazzo, C., Hauchecorne, A., Hampson, J., Kaurola, J., Damski, J., Thölix, L., Langematz, U., Mieth, P., Nissen, K., Grenfell, L., Lahoz, W., Hare, S., and Canziani, P.: EuroSPICE: The European Project on Stratospheric Processes and their Influence on Climate and the Environment Description and brief Highlights, in: SPARC Newsletter No. 21, July 2003, pp. 15-19, 2003.

Austin, J., Shindell, D., Bruhl, C., Dameris, M., Manzini, E., Nagashima, T., Newman, P., Pawson, S., Pitari, G., Rozanov, E., Schnadt, C., and Shepherd, T. G.: Uncertainties and assessments of chemistry-climate models of the stratosphere, Atmos. Chem. Phys., 3, 1-27, 2003, http://www.atmos-chem-phys.net/3/1/2003/.

Austin, J. and Wilson, R.J.: Ensemble simulations of the decline and recovery of stratospheric ozone J. Geophys. Res., 111, D16314, doi:10.1029/2005JD006907, 2006.

Brasseur, G. P., Tie, X., Rasch, P., and Lefèvre, F.: A threedimensional model simulation of the Antarctic ozone hole: Impact of anthropogenic chlorine on the lower stratosphere and upper troposphere, J. Geophys. Res., 102, 8909-8930, 1997.

Carslaw, K. S., Kettleborough, J. A., Northway, M. J., Davies, S., Gao, R., Fahey, D. W., Baumgardner, D. G., Chipperfield, M. P., and Kleinböhl, A.: A vortex-scale simulation of the growth and sedimentation of large nitric acid hydrate particles, J. Geophys. Res., 107(D20), 8300, doi:10.1029/2001JD000467, 2002.

Chipperfield, M. P.: Multiannual simulations with a threedimensional chemical transport model, J. Geophys. Res., 104, 17811805, 1999.

Chipperfield, M. P.: A three-dimensional model study of longterm mid-high latitude lower stratosphere ozone changes, Atmos. Chem. Phys., 3, 1253-1265, 2003, http://www.atmos-chem-phys.net/3/1253/2003/.

Cullen, M. J. P.: The unified forecast/climate model, Meteorol. Mag., 122, 81-94, 1993.

Damski, J., Thölix, L., Backman, L., Taalas, P., and Kulmala, M.: FinROSE - Middle Atmospheric Chemistry Transport Model, Boreal Environ. Res., in press, 2007.

Dhomse, S., Weber, M., Wohltmann, I., Rex, M., and Burrows, J. P.: On the possible causes of recent increases in northern hemispheric total ozone from a statistical analysis of satellite data from 1979 to 2003, Atmos. Chem. Phys., 6, 1165-1180, 2006, http://www.atmos-chem-phys.net/6/1165/2006/.

Egorova, T. A., Rozanov, E., Schlesinger, M., Andronova, N., Malyshev, S., Karol, I., and Zubov, V.: Assessment of the effect of the Montreal Protocol on atmospheric ozone, Geophys. Res. Lett., 28(12), 2389-2392, doi:10.1029/2000GL012523, 2001.

Eyring, V., Butchart, N., Waugh, D. W., et al.: Assessment of temperature, trace species and ozone in chemistry-climate model simulations of the recent past, J. Geophys. Res., 111, D22308, doi:10.1029/2006JD007327, 2006.

Fahey, D. W., Gao, R. S., Carslaw, K. S., Kettleborough, J., Popp, 
P. J., Northway, M. J., Holecek, J. C., Ciciora, S. C., McLaughlin, R. J., Thompson, T. L., Winkler, R. H., Baumgardner, D. G., Gandrud, B., Wennberg, P. O., Dhaniyala, S., McKinney, K., Peter, Th., Salawitch, R. J., Bui, T. P., Elkins, J. W., Webster, C. R., Atlas, E. L., Jost, H., Wilson, J. C., Herman, R. L., Kleinböhl, A., and von König, M.: The detection of large nitric-acid particles in the winter Arctic stratosphere, Science, 291, 1026-1031, 2001.

Fioletov, V. E., Bodeker, G. E., Miller, A. J., McPeters, R. D., and Stolarski, R.: Global and zonal total ozone variations estimated from ground-based and satellite measurements: 1964-2000, J. Geophys. Res., 107(D22), 4647, doi:10.1029/2001JD001350, 2002.

Fioletov, V. E. and T. G. Shepherd: Summertime total ozone variations over middle and polar latitudes, Geophys. Res. Lett., 32, L04807, doi:10.1029/2004GL022080, 2005.

Fortuin, J. P. F. and Kelder, H.: An ozone climatology based on ozonesonde and satellite measurements, J. Geophys. Res., 103(D24), 31 709-31 734, doi:10.1029/1998JD200008, 1998.

Garcia, R. R., Marsh, D., Kinnison, D., Boville, B., and Sassi, F.: Simulation of secular trends in the middle atmosphere 19502003, J. Geophys. Res., 111, doi:10.1029/2006JD007485, in press, 2007.

Hadjinicolaou, P., Jrrar, A., Pyle, J. A., and Bishop, L.: The dynamically driven long-term trend in stratospheric ozone over northern mid-latitudes, Q. J. Roy. Meteor. Soc., 128, 1393-1412, 2002.

Hadjinicolaou P., Pyle, J. A., and Harris, N. R. P.: The recent turnaround in stratospheric ozone over northern middle latitudes: A dynamical modeling perspective, Geophys. Res. Lett., 32, L12821, doi:10.1029/2005GL022476, 2005.

Hall, T. M., Waugh, D. W., Boering, K. A., and Plumb, R. A.: Evaluation of transport in atmospheric models, J. Geophys. Res., 104, 18 815-18 839, 1999.

Kylling, A.: Radiation transport in cloudy and aerosol loaded atmosphere, Ph.D. thesis, University of Alaska, 1992.

Kylling, A., Albold, A., and Seckmeyer, G.: Transmittance of a cloud is wavelength - dependent in the UV-range: Physical interpretation, Geophys. Res. Lett., 24(4), 397-400, doi:10.1029/97GL00111, 1997.

Lin, S.-J. and Rood R. B.: Multidimensional flux-form semilagrangian transport schemes, Mon. Wea. Rev., 124, 2046-2070, 1996.

Manzini, E., Steil, B., Brühl, C., Giorgetta, M. A., and Krüger, K.: A new interactive chemistry-climate model: 2 . Sensitivity of the middle atmosphere to ozone depletion and increase in greenhouse gases and implications for recent stratospheric cooling, J. Geophys. Res., 108(D14), 4429, doi:10.1029/2002JD002977, 2003.

Nagashima, T., Takahashi, M., Takigawa, M., and Akiyoshi, H.: Future development of the ozone layer calculated by a general circulation model with fully interactive chemistry, Geophys. Res. Lett., 29(8), doi:10.1029/2001GL014026, 2002.

Randel, W. J. and Wu, F.: A stratospheric ozone trends data set for global modeling studies, Geophys. Res. Lett., 26, 3089-3092, 1999.

Reinsel, G. C., Miller, A. J., Weatherhead, E. C., Flynn, L. E., Nagatani, R. M., Tiao, G. C., and Wuebbles, D. J.: Trend analysis of total ozone data for turnaround and dynamical contributions, J. Geophys. Res., 110, D16306, doi:10.1029/2004JD004662, 2005.
Rex, M., Salawitch, R. J., von der Gathen, P., Harris, N. R. P., Chipperfield, M. P., and Naujokat, B.: Arctic ozone loss and climate change, Geophys. Res. Lett., 31, L04116, doi:10.1029/2003GL018844, 2004.

Rose, K.: On the influence of nonlinear wave-wave interaction in a 3 -d primitive equation model for sudden stratospheric ings, Contributions to Atmospheric Physics, 56, 1, 14-41, 1983.

Rose K. and Brasseur, G.: A three-dimensional model of chemically active trace species in the middle atmosphere during disturbed winter conditions, J. Geophys. Res., 94(D13), 16387-16403, 1989.

Rummukainen, M., Isaksen, I. S. A., Rognerud, B., and Stordal,F., A global model tool for three-dimensional multiyear stratospheric chemistry simulations: Model description and first results, J. Geophys. Res., 104, 26 437-26 456, 1999.

Sander, S. P., Ravishankara, A. R., Friedl, R. R., et al.: Chemical Kinetics and Photochemical Data for Use in Atmospheric Studies, Evaluation Number 14, JPL Publ. 02-25, 2003.

Santer, B. D., Sausen, R., Wigley, T. M. L., Boyle, J. S., AchutaRao, K., Doutriaux, C., Hansen, J. E., Meehl, G. A., Roeckner, E., Ruedy, R., Schmidt, G., and Taylor, K. E.: Behavior of tropopause height and atmospheric temperature in models, reanalyses, and observations: Decadal changes, J. Geophys. Res., 108, 4002, doi:10.1029/2002JD002258, 2003.

Shepherd, T. G., Plumb, R. A., and Wofsy, S. C.: Preface to JAS Special Issue on the Antarctic Stratospheric Sudden Warming and Split Ozone Hole of 2002, J. Atmos. Sci., 62, 565-566, 2005.

Steil, B., Brühl, C., Manzini, E., Crutzen, P. J., Lelieveld, J., Rasch, P. J., Roeckner,E., and Krüger, K.: A new interactive chemistry-climate model: 1. Present-day climatology and interannual variability of the middle atmosphere using the model and 9 years of HALOE/UARS data, J. Geophys. Res., 108(D9), 4290, doi:10.1029/2002JD002971, 2003.

Steinbrecht, W., Claude, H., Schönenborn, F., McDermid, I. S., Leblanc, T., Godin, S., Song, T., Swart, D. P. J., Meijer, Y. J., Bodeker, G. E., Connor, B. J., Kämpfer, N., Hocke, K., Calisesi, Y., Schneider, N., de la Noë, J., Parrish, A. D., Boyd, I. S., Brühl, C., Steil, B., Giorgetta, M. A., Manzini, E., Thomason, L. W., Zawodny, J. M., McCormick, M. P., Russell, J. M., III, Bhartia, P. K., Stolarski, R. S., and Hollandsworth-Frith, S. M.: Long-term evolution of upper stratospheric ozone at selected stations of the Network for the Detection of Stratospheric Change (NDSC), J. Geophys. Res., 111, D10308, doi:10.1029/2005JD006454, 2006.

Tian, W. and Chipperfield, M. P.: A New coupled chemistry-climate model for the stratosphere: The importance of coupling for future O3-climate predictions, Q. J. Roy. Meteor. Soc., 131, 281-303, 2005.

UNEP: The Montreal Protocol on Substances that Deplete the Ozone Layer as adjusted and/or amended in in London 1990, Copenhagen 1992, Vienna 1995, Montreal 1997, Beijing 1999, Ozone Secretariat, United Nations Environment Programme, http://www.unep.org/ozone, 2000.

Waugh, D. and T. Hall: Age of stratospheric air: Theory, observations, and models, Rev. Geophys., 40(4), 1010, doi:10.1029/2000RG000101, 2002.

Weatherhead, E. C. and S. B. Andersen: The search for signs of recovery of the ozone layer. Nature, 441, 39-45, doi:10.1038/nature04746, 2006.

Weatherhead, E. C., Reinsel, G. C., Tiao, G. C., Jackman, C. H., 
Bishop, L., Hollandsworth Frith, S. M., DeLuisi, J., Keller, T., Oltmans, S. J., Fleming, E. L., Wuebbles, D. J., Kerr, J. B., Miller, A. J., Herman, J., McPeters, R., Nagatani, R. M., and Frederick, J. E.: Detecting the recovery of total column ozone, J. Geophys. Res., 105, 22 201-22 210, 2000.

Williams, K. D., Senior, C. A., and Mitchell, J. F. B., Transient climate change in the Hadley Centre models: the role of physical processes, J. Climate, 14, 2659-2674, 2001.

WMO, Scientific Assessment of Ozone Depletion: 2002, Global Ozone Research and Monitoring Project, Report No. 47, 498 pp., Geneva, 2001.
Wohltmann, I., Rex, M., Brunner, D., and Mäder, J.: Integrated equivalent latitude as a proxy for dynamical changes in ozone column, Geophys. Res. Lett., 32, L09811, doi:10.1029/2005GL022497, 2005.

Yang E.-S., Cunnold, D. M., Salawitch, R. J., McCormick, M. P., Russell III, J., Zawodny, J. M., Oltmans, S., and Newchurch, M. J.: Attribution of recovery in lower-stratospheric ozone, J. Geophys. Res., 111, D17309, doi:10.1029/2005JD006371, 2006. 